Nicolas Kreibich, Lukas Hermwille, Carsten Warnecke, Christof Arens

\title{
An Update on the Clean Development Mechanism in Africa in Times of Market Crisis
}

Originally published in:

Climate and Development, 9 (2017), 2, 178-19o

DOI: $10.1080 / 17565529.2016 .1145102$ 
Nicolas Kreibich $a$,

Lucas Hermwille a

Carsten Warnecke b

Christof Arens a

\section{An Update on the Clean Development Mechanism in Africa in Times of Market Crisis}

a Wuppertal Institute for Climate, Environment and Energy, Germany

b NewClimate Institute, Köln, Germany

* Corresponding author:

Nicolas Kreibich

Wuppertal Institute for Climate, Environment and Energy

Research Group: Energy, Transport and Climate Policy

Döppersberg 19

42103 Wuppertal

Germany

E-mail: nico.kreibich@wupperinst.org

Phone: +49 2022492194

This is the author's version of a work that was accepted for publication. Changes resulting from the publishing process, such as editing, corrections and structural formatting, may not be reflected in this document. Changes may have been made to this work since it was submitted for publication. A definitive version was subsequently published in the Journal cited above. 


\title{
An Update on the CDM in Africa in Times of Market Crisis
}

\begin{abstract}
Africa and in particular African Least Developed Countries (LDCs) have in the past been neglected by the Clean Development Mechanism (CDM) to a large extent. This article reviews the mechanism's performance in the region and highlights current developments. The analysis is based on a quantitative breakdown of data provided by the UNEP DTU CDM Pipeline and was complemented by interviews with selected investors. The findings indicate that despite the various support measures for underrepresented regions, the overall share of African CDM activities continues to be low. The significant rise in the share of Programmes of Activities (PoAs) of recent years cannot make up for the continuing low numbers of African stand-alone projects. Further, the collapse of the compliance market has proved fatal in terms of timing: Ongoing efforts to support the development of a genuine African carbon market were suffocated by the lack of demand for CERs at a moment when capacity building had started to bear fruit. Consequently, instead of being a mitigation tool with significant scale the future role of the CDM in Africa might be limited to the voluntary market while at the same time serving as a tool to foster sustainable development, with mitigation benefits.
\end{abstract}

\section{Key words}

CDM; Africa; least developed countries; climate change; carbon trading

\section{Introduction}

Africa and more specifically African Least Developed Countries (LDCs) have traditionally lagged behind other regions as hosts of mitigation activities under the Clean Development Mechanism (CDM). Alongside general investment barriers in these countries, it took many countries some time to establish the necessary institutional framework. Furthermore, a large majority of the CDM potential in Africa and more so in African LDCs takes the form of relatively small dispersed emission sources. Because of the relatively high upfront costs that are unrelated to the size of the proposed project, covering these emission sources is relatively unattractive in economic terms (see for example Silyan, 2005; Schneider, 2007; Castro and Michaelowa, 2011; Lütken, 2012; Burian and Arens, 2014). Consequently, only South Africa and a number of northern African countries have been successful as host countries so far. Other countries, in particular in
sub-Saharan Africa, have struggled to attract CDM activities despite having large potential for project development (Timilsina, de Gouvello, Thioye and Dayo, 2010; Arens, Burian, Sterk, Schnurr and Beuermann, 2011). With many of these countries suffering from extraordinarily low levels of development and given the fact that the CDM is not only intended to support Annex-I countries in meeting their emission reduction commitments but also to support the projects' host countries in achieving sustainable development, this development is particularly distressing.

This regional imbalance has been repeatedly criticised in the context of the sustainable development benefits the CDM is expected to deliver (see for instance Olsen and Fenhann, 2008; van Asselt and Gupta, 2009; Boyd et al., 2009; Mathur et al., 2014). The Parties to the United Nations Framework Convention on Climate Change (UNFCCC) recognized this fact as early as 2006 and several measures were taken to improve regional distribution in general as well as to support the 
development of CDM activities on the African continent more specifically.

In addition, the European Union (EU) adopted a regulation on the use of Certified Emission Reductions (CERs) in the European Union Emission Trading Scheme (EU ETS) giving preference to CERs from LDC which was expected to have a significant effect on Africa's role in the CDM. With this regulation, the emphasis was laid on carbon credits stemming from LDCs, most of which are located in Africa, raising hopes that the African carbon market might catch up with the other regions in the world.

At the same time, however, the global carbon markets crashed and CER prices plummeted to near zero: The lack of ambitious emission reduction targets in Annex-I countries together with a decline of industrial emissions in the wake of the global financial crisis $2008 / 2009$ resulted in a large oversupply of emission permits, shrinking demand for CERs to historical low levels. The lack of demand from the EU ETS is particularly distressing for the CDM (Gloaguen and Alberola, 2013; Bellassen et al., 2012).

The authors of this paper argue that despite conditions for project development in Africa being particularly favourable due to established local capacities and numerous support measures, all attempts to support the uptake of the CDM in the region have been nullified by the plunge of the global demand for CERs. Building on quantitative and qualitative data of both the demand side and the supply side of the African CDM market, the paper scrutinizes this hypothesis also exploring other potential reasons for the continuing low uptake of the CDM in Africa. Based on this analysis, the paper discusses the future of the CDM in Africa and the lessons that can be learned from this development.

\section{Methodology}

In order to get a comprehensive picture, both the supply and the demand side of the African CDM market were analysed. For the supply side data, information from the vast UNEP DTU CDM/JI Pipeline was collated and analysed (UNEP DTU, 2015). The analysis covers all projects that entered the CDM pipeline before $31^{\text {st }}$ December 2014. This data was complemented by data from a recent survey. Warnecke, Day and Klein (2015) surveyed a representative sample of 1310 CDM projects globally, 79 of which are based in Africa. The survey provides data on the current project status, CER marketing, status of verification and issuance, barriers and costs of the project implementation. Assessing the eventual sustainable development contributions of individual CDM projects, including through the transfer of technologies, is beyond the scope of this article.

The CDM pipeline can be analysed along multiple dimensions that each take a slightly different perspective on the same development:

- $\quad$ the number of projects;

- $\quad$ estimated annual CERs generated;

- or CERs issued cumulatively.

Furthermore, one can look into registered projects only or assess the entire CDM pipeline including projects that are currently at validation and not (yet) registered. Last but not least, one could compare countries on a normalized basis, e.g. by controlling for population, economic activity, or total GHG emissions (Lütken, 2011).

The number of registered projects is suited best to reflect the effort that has gone into the CDM in Africa. Completing a validation can be laborious and relatively costly and thus represents significant commitment on behalf of the project proponents. The number of CERs issued, instead, is just too low to give an adequate picture of the CDM in Africa and the projected annual output in terms of CERs rather reflects the size of the projects than the effort that has gone into developing it.

For the demand side, a two-step approach was taken:

[1] A quantitative analysis of the African CER investor landscape based on UNEP DTU data.

[2] A typology of investors in the African market was developed based on two main factors: The entities' share of the global pipeline and the share of African projects in the entities' pipeline. This led to the identification of three groups of typical investors.

The typology served two purposes. First, it was to provide an overview of what kind of investors are active on the African market. Second, the typology served to identify investors for conducting semistructured telephone interviews. Two organisations of each category were selected for this purpose. The selection of the interviewees of each group was based on simple random sampling. Therefore, the positions expressed in these interviews cannot be considered representative but still provide an insight into the investor landscape of the African carbon market. 
More generally, the data available in the CDM Pipeline has also to be handled with care. There are some significant limitations that have to be considered when interpreting the data for the demand side: The pipeline contains only those investors that received a letter of approval from a buyer country. Later investors or buyers of CERs might just not appear in the pipeline. This is particularly relevant for projects that are being carried out exclusively by participants based in the project's host country, so called unilateral CDM projects (Michaelowa, 2007). In addition, many entities listed as "buyers" are actually also active at the supply side. From the mere fact that a (private or public) institution is listed as a buyer organisation it cannot be concluded to what extent the institution has been involved in the respective project's implementation. Buyer organisations can adopt very different roles: They can be involved from the beginning and support the entire project development process or only function as a mere customer that approaches the project developer when the development process has already been completed. Hence, when speaking of the "demand side", this also includes investors and in some cases even project developers; a clear-cut separation between supply and demand is not possible. For the sake of clarity we will in the following use the term "investor" to refer to all those organisations involved in the purchase of CERs.

\section{African CDM Supply}

The uneven geographical distribution of CDM projects has long been an issue of concern. There is an extensive literature discussing the barriers to project implementation (Arens and Burian, 2012; Arens, Wang-Helmreich, et al., 2011; Byigero, Clancy and Skutsch, 2010; Castro and Michaelowa, 2011; Costantini and Sforna, 2014; Dinar, Rahman, Larson and Ambrosi, 2008; Jung, 2006; Niederberger and Saner, 2005; Okubo and Michaelowa, 2010; Röttgers and Grote, 2014; Spalding-Fecher et al., 2012; Winkelman and Moore, 2011). The general business environment has been identified as one important factor, but there are also CDM specific barriers for the realization of CDM projects: the absolute level of GHG emissions, GHG intensity, institutional capacity, and human capital.

Most African countries and particularly African LDCs fare not very well in most of these. Foreign direct investment is low, and so are absolute emissions and emission intensity. And it took most African countries quite some time to set up the required national institutions and built up human capacities.

Despite these structural disadvantages, it is clear that there is a substantial potential for the CDM in Africa and even in African LDCs (Arens, et al., 2011; De Gouvello, Dayo and Thioye, 2008) and despite numerous efforts to support the CDM in the region (Arens, Wang-Helmreich, et al., 2011; Castro and Michaelowa, 2011; Okubo and Michaelowa, 2010) this potential remains largely untapped.

Looking at the supply of CERs from Africa, the share of African CDM projects is still very low. By the end of 2014, only 191 African CDM projects are registered, representing a share of $2.51 \%$ of the total 7399 registered projects (see Table 1). With respect to African LDCs the situation is even worse. Only 48 registered projects exist, representing $0.63 \%$ of the total. Even if looked at in normalized terms, this is a poor performance since Africa and African LDCs represent around $11 \%$ and $5 \%$ respectively of all non-Annex 1 emissions (WRI, 2015).

The only relatively good performer among African LDCs is Uganda with 14 registered projects. For comparison, LDCs outside of Africa have attracted some more attention (Bangladesh: 4; Bhutan: 4; Cambodia: 10; Lao PDR: 11; Nepal: 6). Figure 1 shows that the share of CDM projects has been largely stable over the years and it continuously stays at a very low level.

It is remarkable that not even the EU decision to restrict the eligibility of CERs for the EU ETS had significant effect on the CDM supply from African LDCs, since the EU ETS is by far the single largest source of demand for CERs. In April 2009, the EU decided to restrict the eligibility of CERs from post2012 registered projects to those based in a LDC (European Parliament and European Council, 2009).

For African projects, registrations surged in late 2012 right before the end of the exclusion deadline (see figure 2). Project registrations from African LDCs however, do not present a significant reaction. The absence of a similar spike is no surprise since the ETS regulation does not affect these projects, but one would have expected an increased uptake of projects entering the CDM pipeline after the announcement in April 2009. This is, however, not the case. Apparently, demand for CERs in the EU ETS is already saturated to such an extent that there is simply no need for more CDM projects. 
Table 1: Overview of CDM projects in Africa by country and type of project (based on UNEP DTU, 2015).

\begin{tabular}{|c|c|c|c|c|c|c|c|c|c|c|c|c|c|c|c|c|c|c|c|c|c|c|c|}
\hline & & & & & & & & & & & Regi & stere & ed pro & ojects & ts by $t$ & type & of $p$ & rojec & & & & & \\
\hline 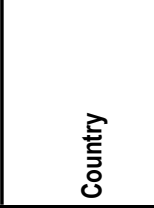 & 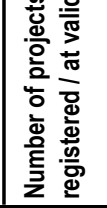 & 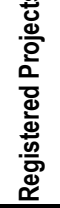 & 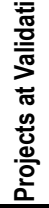 & 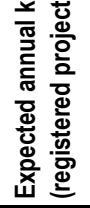 & 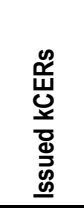 & 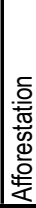 & 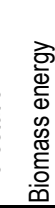 & 志 & 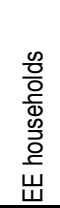 & 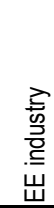 & 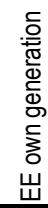 & 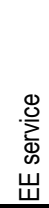 & $\begin{array}{l}\text { 흐 } \\
\text { 흘 } \\
\text { 흫 } \\
\text { क } \\
\text { 出 }\end{array}$ & 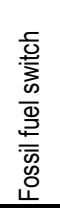 & 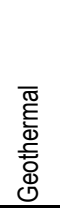 & 음 & 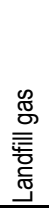 & 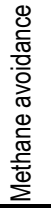 & ণ & 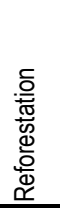 & $\frac{2}{0}$ & 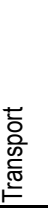 & 总 \\
\hline Algeria & $2 / 0$ & 2 & 0 & 641 & 0 & & & & & & & & & & & & & & 2 & & & & \\
\hline Angola* & $1 / 4$ & 1 & 4 & 126 & 0 & & & & & & & & & & & 1 & & & & & & & \\
\hline Burundi & $3 / 0$ & 3 & 0 & 246 & 0 & & & & & & & 3 & & & & & & & & & & & \\
\hline Cameroon & $2 / 2$ & 2 & 2 & 193 & 69 & & & & & & & & & & & & 2 & & & & & & \\
\hline Cape Verde & $1 / 0$ & 1 & 0 & 67 & 0 & & & & & & & & & & & & & & & & & & 1 \\
\hline Congo DR* & $2 / 0$ & 2 & 0 & 179 & 0 & 1 & & & & & & & & & & & 1 & & & & & & \\
\hline Côte d'Ivoire & $5 / 0$ & 5 & 0 & 1,245 & 0 & & 2 & & & & & & 1 & & & & 2 & & & & & & \\
\hline Egypt & $19 / 3$ & 19 & 3 & 4,183 & 13,557 & & 2 & & & 2 & 1 & & 1 & 2 & & & 2 & & 4 & & & & 4 \\
\hline Ethiopia* & $2 / 0$ & 2 & 0 & 126 & 73 & & & & & & & & & & & & 1 & & & 1 & & & \\
\hline Gambia* & $0 / 1$ & 0 & 1 & 0 & 0 & & & & & & & & & & & & & & & & & & \\
\hline Ghana & $2 / 2$ & 2 & 2 & 2,672 & 0 & & & & & & & & & & & & & 1 & & & & & \\
\hline Kenya & $20 / 3$ & 20 & 3 & 3,269 & 297 & & 2 & & & 1 & & & & & 4 & 2 & & 1 & & 5 & & & 5 \\
\hline Lesotho* & $1 / 0$ & 1 & 0 & 34 & 21 & & & & 1 & & & & & & & & & & & & & & \\
\hline Liberia* & $1 / 0$ & 1 & 0 & 94 & 0 & & & & & & & & & & & & 1 & & & & & & \\
\hline Libya & $2 / 0$ & 2 & 0 & 363 & 0 & & & 1 & & & & & & & & & & & & & 1 & & \\
\hline Madagascar* & $3 / 0$ & 3 & 0 & 85 & 85 & & & & & & & & & & & 2 & & & & & 1 & & \\
\hline Malawi* & $2 / 0$ & 2 & 0 & 71 & 0 & & & & 2 & & & & & & & & & & & & & & \\
\hline Mali ${ }^{*}$ & $1 / 0$ & 1 & 0 & 188 & 0 & & & & & & & & & & & 1 & & & & & & & \\
\hline Mauritius & $2 / 0$ & 2 & 0 & 114 & 107 & & & & & & & & & & & & 1 & & & & & & 1 \\
\hline Morocco & $15 / 3$ & 15 & 3 & 1,696 & 419 & & 3 & & & & & & & & & & 2 & 1 & & & 2 & & 7 \\
\hline Mozambique* & $2 / 1$ & 2 & 1 & 216 & 0 & & & & 1 & & & & & & & & & & & 1 & & & \\
\hline Namibia & $2 / 0$ & 2 & 0 & 17 & 0 & & & & & & & & & & & & 1 & 1 & & & & & \\
\hline Niger* & $1 / 0$ & 1 & 0 & 25 & 0 & & & & & & & & & & & & & & & 1 & & & \\
\hline Nigeria & $10 / 2$ & 10 & 2 & 6,702 & 1,747 & & 1 & & 1 & & & & & 1 & & 1 & 2 & & & & & & \\
\hline Rwanda* & $4 / 0$ & 4 & 0 & 78 & 23 & & & & 2 & & & & & & & & & & & & 2 & & \\
\hline Senegal ${ }^{*}$ & $4 / 1$ & 4 & 1 & 362 & 0 & 1 & 2 & & & & & & & & & & & & & & & & 1 \\
\hline Sierra Leone* & $1 / 0$ & 1 & 0 & 56 & 0 & & 1 & & & & & & & & & & & & & & & & \\
\hline South Africa & $55 / 14$ & 55 & 14 & 9,783 & 9,288 & & 5 & & 3 & 3 & 7 & 1 & & 3 & & 2 & 7 & 3 & 5 & & 5 & & 10 \\
\hline Sudan* & $1 / 1$ & 1 & 1 & 92 & 0 & & & & & & & & & & & & & & & & & & 1 \\
\hline Swaziland & $0 / 1$ & 0 & 1 & 0 & 0 & & & & & & & & & & & & & & & & & & \\
\hline Tanzania* & $3 / 2$ & 3 & 2 & 223 & 93 & & 1 & & & & & & & & & 1 & 1 & & & & & & \\
\hline Tunisia & $6 / 2$ & 6 & 2 & 1,180 & 481 & & 1 & & & & & & & & & & 2 & & & & & 1 & 2 \\
\hline Uganda* & $14 / 5$ & 14 & 5 & 1,124 & 1,585 & 1 & & & & & & & & & & 5 & 1 & 1 & & 6 & & & \\
\hline Zambia* & $2 / 3$ & 2 & 3 & 141 & 44 & & & & 1 & & & & & & & 1 & & & & & & & \\
\hline Zimbabwe & $1 / 0$ & 1 & 0 & 474 & 0 & & & & & & & & & & & & & & 1 & & & & \\
\hline Total & $192 / 50$ & 192 & 50 & 36,065 & 27,889 & $\overline{3}$ & 20 & 1 & 11 & 6 & 8 & 4 & 2 & 6 & 4 & 16 & 26 & 8 & 12 & 14 & 11 & 1 & 32 \\
\hline
\end{tabular}

CDM Programmes of Activities (PoAs) have been proposed to be more adequate to leverage the smallerscale CDM potential. PoAs feature a two-level structure: Small component project activities (CPAs) that would not be implemented individually due to out-ofscale transaction costs can be aggregated under the roof of one programme. Only the programme itself has to be validated and demonstrate additionality, not every activity individually. The recent uptake of PoAs is therefore a positive development. In 2012, the development of PoAs and their registration accelerated drastically, not only worldwide, but also in Africa. Already early on, PoAs were developed in Africa and especially in African LDCs. As of December 2014, 241 PoAs have been registered including 20 multi- 


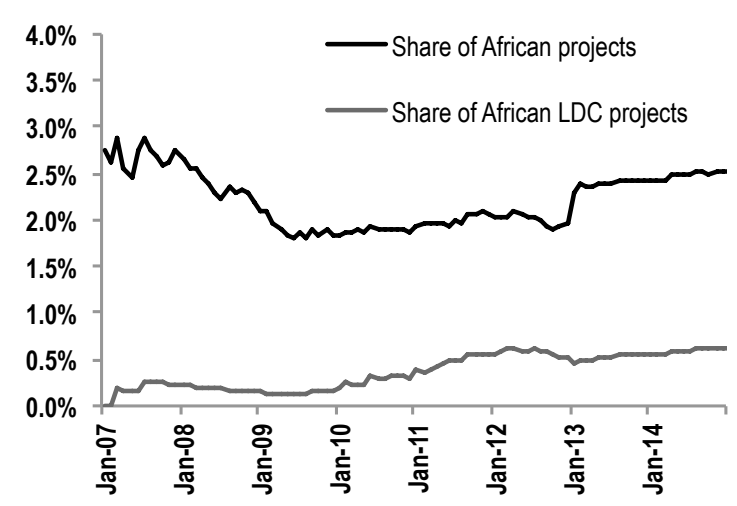

Figure 1: Share of registered African and African LDC's projects from January 2007 till December 2014 (based on data from UNEP DTU, 2015).

country PoAs. 93 of these are situated in Africa, and 32 of them in African LDCs (see Table 2).

While this development appears promising at first, a more detailed look reveals that also PoAs do not fully unlock Africa's mitigation potential. Many of the PoAs have only one (25) or two (18) CPAs registered. Furthermore, the strong uptake of renewable energy
PoAs in South Africa is largely driven by the South African renewable energy programme REIPPPP (Department of Energy - Republic of South Africa, 2015), rather than by demand for CERs. Still the success of the South African case demonstrates that, conditional to sufficient demand, the PoA modality works for the African continent at least in principle.

In Africa, CDM activities are spread across a wide range of sectors, with landfill gas and wind power having the largest share in terms of project numbers. African LDCs deserve a closer look as numerous sectors still remain completely untapped. CDM projects are registered in only 10 of 27 sectors as categorised by UNEP DTU. In descending order of the number of registered projects, these are: hydro power, reforestation, energy efficiency in households, landfill gas, biomass energy, afforestation, energy efficiency in the service sector, solar, wind, and methane avoidance. Wind power, which makes up for over $32 \%$ of all registered CDM projects, is only represented with two projects in African LDCs. Among PoAs, energy efficiency in households and solar power programmes are particularly prolific.
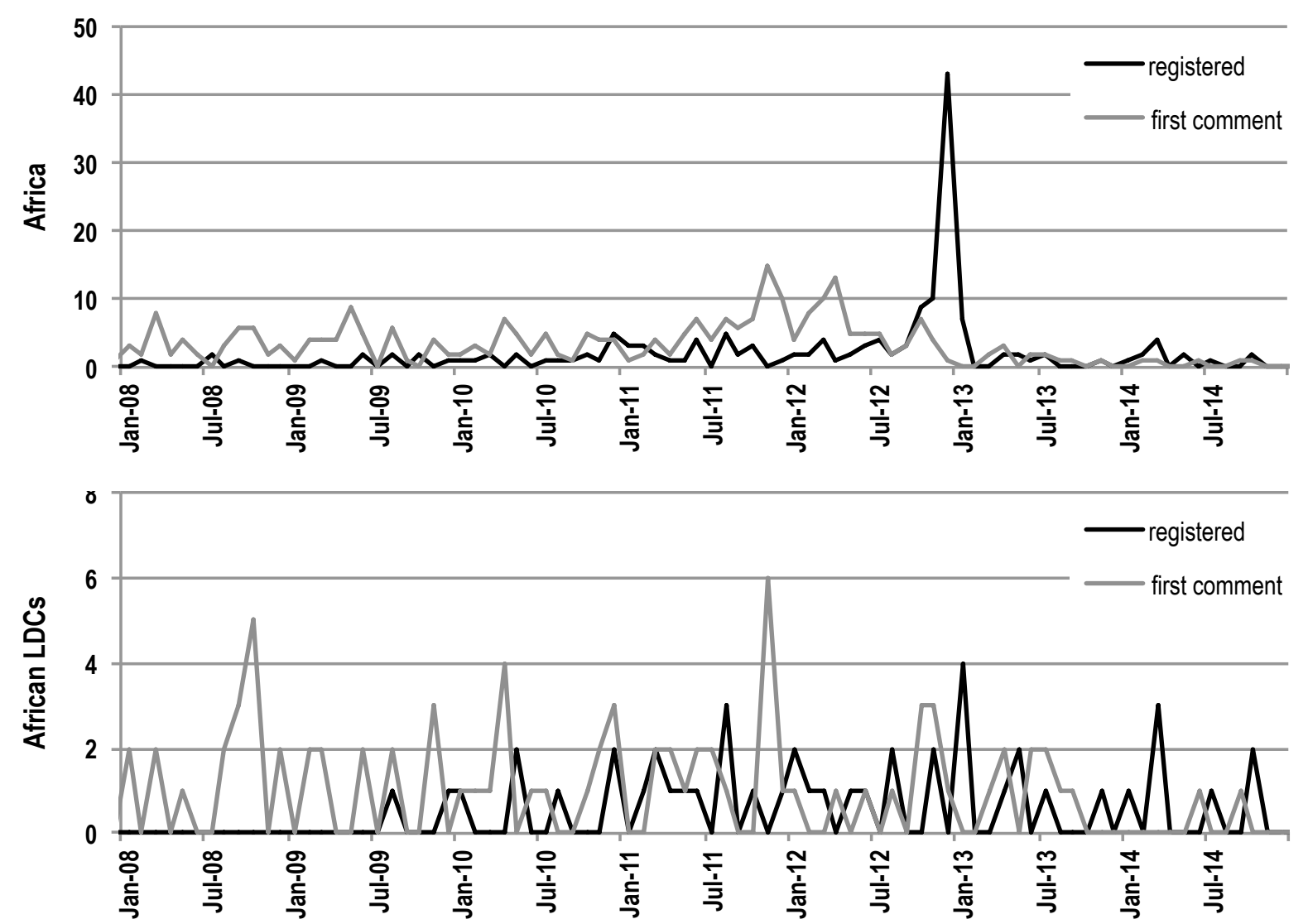

Figure 2: Number of projects entering the CDM pipeline and registered per month (based on UNEP DTU 2015). 
Table 2: Overview of CDM projects in Africa by country and type of project (based on UNEP DTU, 2015). Note that Multi-Country PoAs are only counted in their primary host country as listed in the PoA pipeline.

\begin{tabular}{|c|c|c|c|c|c|c|c|c|c|c|c|c|c|c|c|}
\hline & & & & & & & & CPA & s by & Type & & & & & \\
\hline 趌 & 里 & 员 & 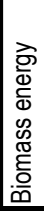 & 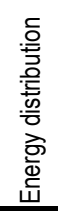 & 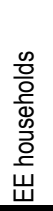 & 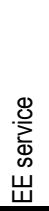 & $\begin{array}{l}\frac{0}{0} \\
\text { 을 } \\
\text { 음 } \\
\text { क } \\
\text { ய }\end{array}$ & 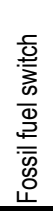 & 옿 & 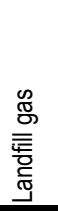 & 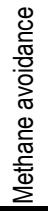 & 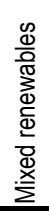 & $\begin{array}{l}\overline{0} \\
\bar{O}\end{array}$ & $\begin{array}{l}\text { 등 } \\
\text { के } \\
\text { की } \\
\text { 듈 } \\
\text { Е }\end{array}$ & $\stackrel{\text { 을 }}{3}$ \\
\hline Burkina Faso* & 2 & 1 & & & 1 & & & & & & & & & & \\
\hline Burundi* & 2 & 1 & & & 1 & & & & & & & & & & \\
\hline Cameroon & 0 & 1 & & & 1 & & & & & & & & & & \\
\hline Chad* & 0 & 1 & & & 1 & & & & & & & & & & \\
\hline Congo DR* & 2 & 2 & & & 2 & & & & & & & & & & \\
\hline Côte d'Ivoire & 1 & 4 & & & 4 & & & & & & & & & & \\
\hline Egypt & 2 & 4 & & & & & & 1 & & & & & & 3 & \\
\hline Ethiopia* & 3 & 8 & & & 8 & & & & & & & & & & \\
\hline Ghana & 5 & 8 & & & 5 & & & & & 1 & 1 & & 1 & & \\
\hline Kenya & 14 & 27 & & 1 & 20 & & & & 2 & & 2 & & 2 & & \\
\hline Liberia* & 0 & 2 & & & 2 & & & & & & & & & & \\
\hline Madagascar* & 1 & 24 & & & 24 & & & & & & & & & & \\
\hline Malawi* & 5 & 9 & & & 9 & & & & & & & & & & \\
\hline Mali $^{*}$ & 1 & 1 & & & 1 & & & & & & & & & & \\
\hline Morocco & 3 & 3 & & & & & & & & 1 & & & 1 & & 1 \\
\hline Mozambique* & 1 & 4 & & & 4 & & & & & & & & & & \\
\hline Namibia & 0 & 1 & & & 1 & & & & & & & & & & \\
\hline Nigeria & 3 & 14 & & & 14 & & & & & & & & & & \\
\hline Rwanda* & 4 & 15 & & & 14 & 1 & & & & & & & & & \\
\hline Senegal" & 2 & 2 & & & 2 & & & & & & & & & & \\
\hline Sierra Leone* & 0 & 1 & & & 1 & & & & & & & & & & \\
\hline Somalia* & 0 & 1 & & & 1 & & & & & & & & & & \\
\hline South Africa & 31 & 56 & 1 & & 4 & 2 & 1 & & 1 & 1 & 1 & & 40 & & 5 \\
\hline Sudan* & 1 & 1 & & & & & & & & & 1 & & & & \\
\hline Tanzania* & 2 & 3 & & & & & & & & & & 2 & 1 & & \\
\hline Togo* & 1 & 2 & & & 2 & & & & & & & & & & \\
\hline Tunisia & 1 & 8 & & & & & & & & & & & 8 & & \\
\hline Uganda* & 4 & 21 & & & 5 & 3 & & & & 8 & 4 & & 1 & & \\
\hline Zambia* & 2 & 6 & & & 6 & & & & & & & & & & \\
\hline Zimbabwe & 0 & 1 & & & 1 & & & & & & & & & & \\
\hline Total & 93 & 232 & 1 & 1 & 134 & 6 & 1 & 1 & 3 & 11 & 9 & 2 & 54 & 3 & 6 \\
\hline
\end{tabular}

As mentioned before, the number of projects that have gone through verification and received first CERs is disproportionately low. Consequently, there is a large gap between what had been expected in terms of emission reductions and what has actually been certified (see figure 3 ). As of $31^{\text {st }}$ December 2014 only 48 African CDM projects and only $12 \mathrm{CDM}$ projects in African LDCs have been issued credits. This represents only $1.56 \%$ and $0.02 \%$ respectively of total CERs issued. While on global average only $36 \%$ of all registered projects have been issued CERs to date, the rate is even lower in Africa (25\%) and African LDCs $(25 \%)$.

Warnecke et al. (2015) have surveyed 70 registered CDM projects in Africa (42 in South Africa and 29 in the group of sub-Saharan Africa comprising Kenya, Rwanda, Senegal, and Uganda). Only 44\% of these projects have achieved full implementation yet (global average is $85 \%$ ). This may reflect the fact that the majority of sub-Saharan African projects surveyed were registered only relatively lately, in 2012 and the group includes a higher proportion of PoAs than the average 


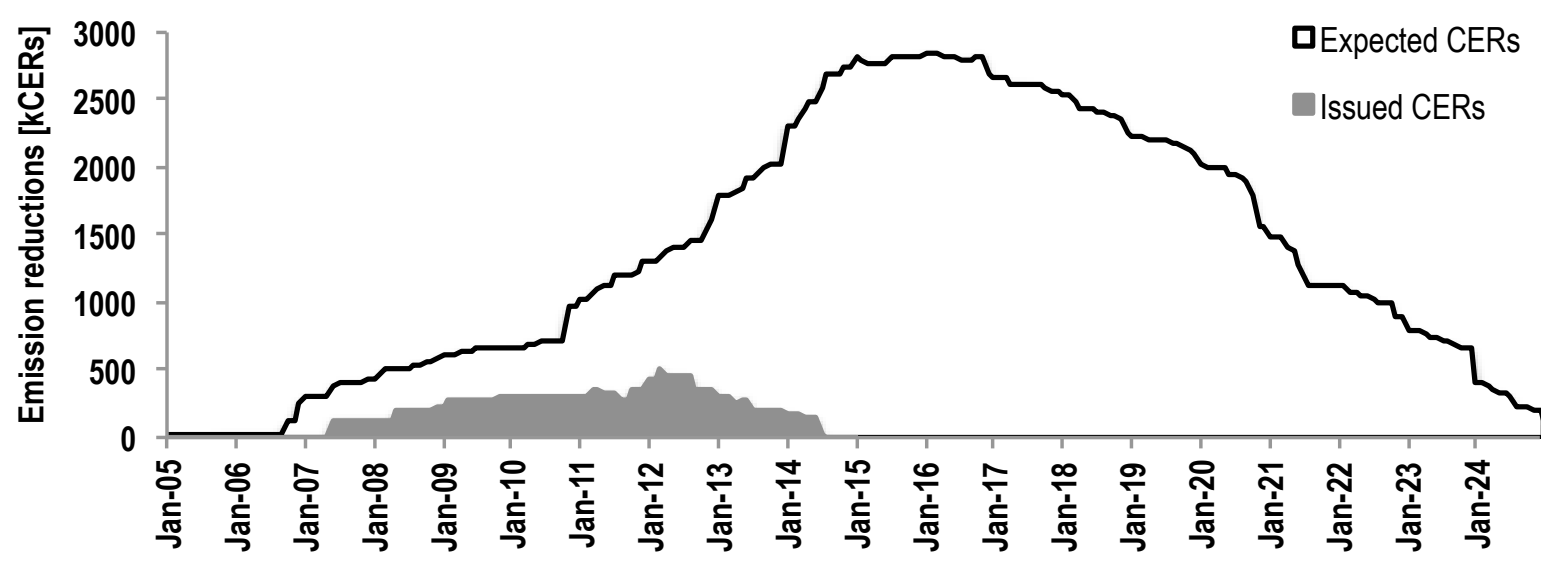

Figure 3: Expected and issued CERs from CDM projects located in Africa (based on UNEP DTU 2015).

- only 37 per cent of the African PoAs have been implemented technically and only 15 per cent are operational. However, also 11 per cent of the South African projects admitted that they are currently unable to forecast their situation for the next 12 month (Warnecke et al. 2015). Also, only 29 per cent of the African projects surveyed currently are in regular operation. Still, African project participants are relatively optimistic that they can resume to a regular operation within the next year: 10 per cent of South African projects and 6 per cent of the sub Saharan projects assume that they can start or resume regular operation within the next year. Relatively high expectations exist that alternative support will be available to the projects to alleviate the drop of CER prices $(39 \%$ in South Africa, $43 \%$ in SSA). Despite the grave market situation, 74 per cent of African projects surveyed still expect a positive return to their investment.

In the recent past, a number of initiatives have been undertaken to support the development of CDM projects in hitherto underdeveloped regions. The possibility to make use of standardised baseline $16.5 \mathrm{cms}$ (SBs) for additionality testing and crediting was created. SBs have the potential to facilitate project development and to lower transaction costs, thus easing two important barriers for CDM project development in Africa (Mersmann and Arens, 2012). In this regard, it is an encouraging sign that the first two registered SBs were developed for African projects. However, the regulatory framework for Standardised Baselines is still work in progress. While the basic body of regulation is there, the way how best to determine baseline and additionality thresholds is not yet decided upon (Hermwille, Arens and Burian, 2013).
Furthermore, methodologies have been developed topdown to cater for Africa's small scale CDM potential with some success.

The CDM Loan Scheme supports projects in their early development stages by providing early finance. It was officially launched in April 2012 and has since provided loans to 72 projects, 51 of which are based in Africa and 36 in African LDCs (CDM Loan Scheme, 2015). These figures indicate that it is indeed supporting project development. Yet it has to be seen whether or not the supported projects can actually thrive in times of ultra-low CER prices. Providing grants instead of loans as was initially proposed (Castro and Michaelowa, 2011) could become necessary when the carbon price does not recover.

It has been argued that a lack of capacity has been a major barrier to the CDM in Africa and other underrepresented regions (e.g. Arens and Burian, 2012; Byigero et al., 2010). Numerous efforts have been made among others under the Nairobi Work Programme and through the Regional Collaboration Centres in Lomé and Kampala to built up institutional capacities in the region.

The efforts have been fruitful to some extent. A total of 73 PDD consultants with head offices on the African continent have been involved in project development. 21 of these are listed as dedicated CDM or PoA consultants in the UNEP DTU CDM pipeline. Their contribution culminated in 2012, when African consultants were involved in 35 of 50 registered projects. However, the downturn on the international carbon markets also threatens these capacities. In 2013 and 2014 only 4 and 2 projects with involvement of Afri- 
can PDD consultants have been registered respectively.

A final word on the success of the various capacity building efforts is difficult. What can be observed is that they do take up lessons learnt from capacity building initiatives. In working with local firms that can provide ongoing CDM consulting and advisory services after a support programme has stopped, integrating local banks and financial institutions and a promotion of regional cooperation on technical and regulatory issues some of the major bottlenecks have been addressed (Arens, Wang-Helmreich et al.., 2011; Okubo and Michaelowa, 2010). However, the fate of the Clean Development Mechanism in Africa first and foremost depends on the demand side. Under the current situation is it still reasonable to provide further capacity building and upfront finance for ever more projects? Or does this kind of support promise business opportunities which the market cannot keep?

\section{The Investors' Perspective}

As discussed above, the investors' data provided by the CDM pipeline has to be handled with care. As of February 2015, the number of African projects with information on the investor available in the pipeline data is limited to a total number of 138 projects. The number of entities involved in these projects amounts to 128 . In $43 \%$ of the projects in the African pipeline no investor is listed. This share of so called unilateral projects roughly corresponds with the global average (38\%). Interestingly, for projects in African LDCs the situation is slightly different: Only $19 \%$ of the LDC projects do not specify an investor. One reason could be that investors communicate their supportive role in these projects more proactively for promotional reasons, since projects carried out in LDCs are often associated with strong sustainable development benefits. Furthermore, LDCs might lack the human capacities and availability of domestic capital for unilateral project development and implementation, making it more relevant for these projects to find foreign investors. The limited number of unilateral projects in African LDCs, many of which are located in sub-Saharan Africa, seems to reflect a much more limited potential for unilateral projects in sub-Saharan Africa as predicted in earlier studies (Michaelowa, 2007; Fay, Kapfudzaruwa, Na and Matheson 2012; Wei, 2011; TERI, 2012).
The spectrum of CDM investors active in Africa is summarized in table 3 above. The largest share of investors active on the African carbon market is based in Japan, the United Kingdom and Germany. The investors operate in very diverse sectors. The largest group consists of entities whose main business is the carbon market. A second category of investors comprises public institutions such as national governments and ministries, mainly from European countries. Another large group of investors are organisations from the energy sector, including utilities, energy companies as well as businesses from the oil and gas sector. Also the finance sector has been engaged in the African carbon market. The list of investors comprises both private entities and public ones. However, the private sector plays a pivotal role: $75 \%$ of the investors involved in African projects are private entities.

Warnecke et al.. (2015) have surveyed projects whether they have signed an Emission Reduction Purchase Agreement (ERPA) to sell CERs. The findings indicate that 33 per cent of the African CDM projects have not signed an ERPA with a CER buyer at any stage. This resembles the global picture with an average of 29 per cent. Public entities have been involved in 35 per cent the African ERPAs. However, for subSaharan Africa this share is significantly higher (63\%) and also considerably above the global average.

Since single projects can have multiple investors and one investor can be involved in several projects, the number of participations of investors does not necessarily correspond to the total number of projects. The analysis of the scope and scale of the engagement of these investors reveals that the African carbon market comprises a large number of investors involved in a small number of projects. While the number of investors who are participating in several African CDM projects is rather small, a large part of the organisations $(41 \%)$ is limiting its activities in the African carbon market to one CDM project. About one quarter of the investors $(26 \%)$ is further engaged in a maximum of two African projects while the remaining are active in three or more African projects (UNEP DTU, 2015).

This situation is reflected in figure 4. It shows a distribution of the entities listed as investors in the CDM pipeline with regards to the overall number of CDM projects they are involved in and the share of African projects in their respective CDM portfolio. All investors that are involved in at least one African project were considered. 
Table 3: Overview of CDM investors in Africa by sector and country of origin (based on UNEP DTU 2015).

\begin{tabular}{|l|c|l|c|}
\hline \multicolumn{3}{|l|}{ Overview of Investors per Sector and Country } & \\
Sector & Investors & Country & Investors \\
\hline Carbon market & 33 & Japan & 20 \\
Public & 20 & UK & 13 \\
Utility & 18 & Germany & 12 \\
Oil and Gas & 11 & Italy & 12 \\
Energy & 10 & France & 9 \\
Bank/Finance & 11 & Spain & 7 \\
Cement & 6 & Switzerland & 7 \\
Consumer & 4 & Norway & 6 \\
Technology & 4 & Denmark & 5 \\
Consultancy & 2 & Netherlands & 4 \\
Agriculture & 1 & other (less than 4 investors per country) & 33 \\
Development & 1 & & \\
Engineering & 1 & & \\
Innovation & 1 & & \\
Insurance & 1 & & \\
Metals & 1 & & \\
Nutrition & 1 & & \\
Steel & 1 & & \\
Waste & 1 & & \\
\hline
\end{tabular}

Based on this distribution a typology of investors on the African carbon market was developed. Three typical groups of investors can be identified:

- The Large Global Player: This group comprises entities involved in a large number of CDM projects globally but whose engagement on the African carbon market remains very limited. There are twenty entities engaged in the African carbon market who are active in 50 or more CDM projects worldwide. The group comprises both private companies as well as public entities.

- The Global Player with a Focus on Africa: The second group of investors engaged in Africa is the global player with a particular focus on African CERs. This type of investor is engaged in projects at a global scale; a minimum threshold was set at eight project involvements globally with at least one of the projects being implemented in Africa.

- The Small Africa Specialist: Apart from the first two groups there is a significant number of actors who are specialised in African projects. The majority of these entities are limiting their global activities to a very small number of projects, one or two in most cases.
Based on this classification, telephone interviews have been conducted; two interviews were held with each type of investor. The interviews are to complement the quantitative data in order to get a more comprehensive picture of Africa's investor landscape.

One of the large global players interviewed is a major European gas and energy company whose engagement in the CDM is driven by compliance reasons. The second large global player interviewed is a European development bank that developed a purchase programme for compliance buyers.

Both global players with focus on Africa that have been interviewed are engaged in CDM projects around the globe, with Africa being one key region of their activities. While one company has been managing carbon funds mainly for compliance buyers, the second organisation interviewed is primarily offering voluntary carbon offsetting solutions.

Interviews have also been held with two small Africa specialists whose CDM activities are exclusively focusing Africa. Both companies have been actively engaged in the development of their CDM projects and could benefit from former activities in the region. While one small Africa specialist could built on several years of experience in developing African forestry projects outside the CDM, the second has vast experience as a project developer in the region. 


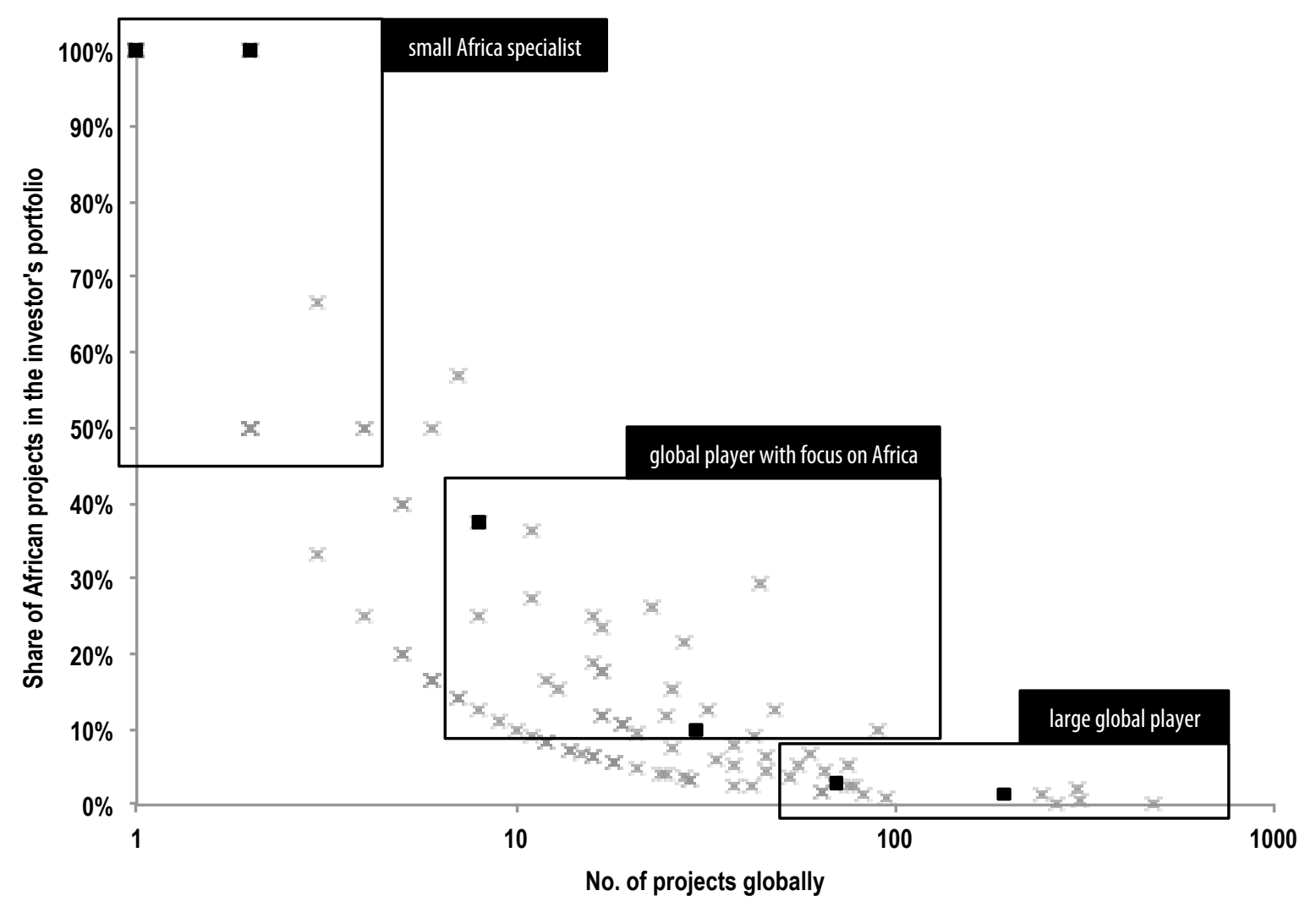

Figure 4: Three different groups of investors at the African carbon market. Black squares indicate interviewed entities. (based on data from UNEP Risø, 2013). ${ }^{1}$

The telephone interviews revealed that motives for investing in Africa are diverse: The large global players stated that there was little financial incentive to invest in the African carbon market before the plans to exclude CERs from non-LDCs from the EU ETS after 2012 became public. Only after that, their focus shifted towards LDCs. One respondent stated that even a dedicated strategy for investing in Africa was developed in 2011. A second common motivation to invest in Africa for large global players was to diversify the project portfolio. The crash of CER prices on international carbon markets hit these players badly. The Africa strategy of one of the respondents was discontinued in 2012 when price levels dropped. Instead, a plan to phase-out existing purchase activities was developed together with a strategy on how to proceed with existing projects.

Among the global players with a focus on Africa engagement in the region was due to different reasons depending on the entities' orientation and business model. The first investor interviewed is using the CERs for the voluntary market to offset emissions from individuals and companies. According to the in- terviewee, the large sustainable development contributions of African projects represent a central reason for the engagement in the region. The second entity of this group has a multiple role: The company is managing a CER purchase fund while at the same time developing own projects. Furthermore, it is active in the voluntary market. With regard to its compliance market activities, the company's main motivation for the engagement in Africa were the large unexploited project potentials. In LDCs, the engagements' aim was primarily to maintain access to the EU ETS.

The global players with a focus on Africa made different experiences with the global carbon market turndown. While the company active on the compliance market was hit badly by the lack of demand, the developments on the compliance markets had only limited repercussions for the entity focusing the voluntary market: According to one interviewee, the prices in the voluntary market are still stable and individuals are willing to pay a defined price independently from the price level on the compliance market. This allows to continue the implementation of projects. However, the voluntary market players are also experiencing the 
consequences of the current market situation, as the search for large business investors for scaling-up existing projects became more difficult.

The third group of investors, the small Africa specialist, gave more particular reasons for their engagement: experiences from ongoing activities in the region, personal contacts as well as local expertise and partners provided the ground for project implementation. Also the small Africa specialist group is relatively optimistic that market prices will recover. Still, they are making diverse experiences in the current crisis: While the project of one company had to be put on hold due to the price developments, the second company that is focusing the African forestry sector mentioned not to suffer directly from the market developments despite part of its activities being directly linked to the global compliance market. With forestry credits being excluded from the EU ETS ever since, the price development in the scheme has not negatively affected these projects. The company is even continuing its activities to get a new CDM project in Africa validated.

In the acute crisis of international carbon markets, CERs from African projects do not receive any special treatment. They are not achieving prices any higher than those from other regions. One interviewee stated that there is no "real market price" at the moment as prices are below the abatement costs of projects, in particular for African projects. There seems to be a common understanding among the market participants that CERs cannot be traded below their abatement costs, resulting in very small numbers of transaction activities. According to one interviewee, these transactions are limited to public purchase programmes such as the World Bank's Carbon Initiative for Development (CiDev) and voluntary market players at prices between 5 and $15 \mathrm{EUR} / \mathrm{tCO}_{2} \mathrm{e}$. Also, Warnecke et al. (2015) found that $75 \%$ of the African projects surveyed could continue their verification and issuance activities for a CER price of 10 EUR or less.

In the current situation, investors are able to define purchase criteria beyond pure price considerations. These criteria vary between investors from the voluntary market and those from the compliance market: For the voluntary market, the price is defined by the project type involved and directly related to the specific project and its non-carbon benefits. For compliance purchase activities, in contrast, the price is more dependent on whether the project is being implemented in an LDC and if it is targeting a specific sector. How- ever, according to one interviewee, investors focusing the compliance market are partly also willing to pay a higher price for CERs from projects with large sustainable development benefits for CSR-reasons. Hence, while the set-up of the individual project seems to be crucial for the price arrangements, the region as such does not directly influence the price.

\section{Conclusions}

The analysis of the African supply side shows that despite the preferential treatment of CERs from LDCs in the EU ETS after 2012 and numerous support measures in the region the CDM in Africa in general and in African LDCs in particular is still underperforming compared to other regions. Neither the share of registered nor the share of proposed projects in the CDM pipeline has increased substantially.

The uptake of PoAs in recent years can however be considered a positive trend: A considerably large share of the registered programmes is located in Africa, many of them in African LDCs. PoAs can therefore be considered to have mitigated some of the regional bias of the CDM towards large emerging economies (see also Bayer, Pinkerton and Urpelainen, 2014).

Yet even the humble achievements of the African CDM pipeline are now called into question. Many projects feature extraordinarily long delay times without having been issued any CERs yet. This raises the question whether these projects are being implemented at all or if the delay is due to procedural difficulties.

The exclusion of CERs from non-LDC projects registered after 2012 in the EU ETS could have had a significant effect for the investment in African LDCs. Some large players of the global carbon market even developed genuine strategies to strengthen their engagement in the region. However, with the downturn of international carbon markets, the compliance market segment has completely collapsed and consequently most large scale investors have now started phasing out their activities. This illustrates just how fatal the timing was for the African carbon market. The moment when the various initiatives seemed to take first effects, when projects were starting to run and capacities had finally been developed, the market was hit by collapsing prices.

In the light of this development, most interviewees supposed that the CDM will not recover from the cri- 
sis. Instead, it is expected to reduce into a niche market with limited carbon mitigation potential. Voluntary carbon offsetting could likely account for some of this potential. For those investors that (partly) cater for the voluntary carbon market the situation is less tense. While much smaller in scale, this market can sustain prices at a level that makes projects economically viable. The second gleam of hope are institutional investors and public purchase programmes such as CiDev who continue to buy CERs on price levels that enable continued project operation. In this niche market, Africa could well play an important role. Both public purchase programmes and voluntary markets demand high quality projects with significant sustainable development benefits. The African carbon market has a rich potential for such projects.

From the African perspective it seems to be clear: As a mitigation tool, the CDM has reached an impasse. Still, it may survive as a tool to promote sustainable development providing significant contributions in terms of climate change mitigation. In order to be successful in this regard, however, the mechanism's contributions to technology transfer as one key element in the promotion of sustainable development must be further improved. As recent literature has shown, the CDM's technology transfer impacts vary across project types and differ significantly by host country (Murphy, Kirkman, Seres and Haites, 2015; Spalding Fecher et al., 2012; Das, 2011; Seres, Haites and Murphy, 2010). While many projects specify technology transfer benefits in their PDDs, these contributions are often limited to the transfer of technical equipment and training for technology operation and maintenance with only a small number of activities provide strong contributions to technological learning and capability building (Das, 2011).

To properly assess the CDM's performance as a tool to promote sustainable development in Africa specifically, further research is needed. Such research should build on a broad definition of technology transfer as a process that goes beyond the mere transfer of technology and equipment by also covering the building of capacity and knowledge to optimize technologies according to local circumstances, to adapt it to alternative uses as well as to innovate from these by designing and developing new technologies (Mersmann and Hermwille, 2014; Byrne, Smith, Watson and Ockwell, 2011).

With the CDM potentially being converted into a niche market, the question raises how to best make use of the capacities that have been established in Africa. There might be significant potential for using these capacities in the design and implementation of national climate policies. Also, with the establishment of new climate change mitigation mechanisms under the post-2020 agreement local expertise might well be needed in the future. However, it remains to be seen how CDM specific knowledge can be fed into the future processes aimed at tapping emissions in in entire sectors.

More generally, as the example of the African CDM and the findings of this paper have indicated, a more careful analysis of developments at different policy levels is needed in the future. Building local capacities and providing regional support must not only address local needs and challenges but also properly take into account the developments at the global level. Raising high expectations on which the international level cannot deliver may not only result in resources being spend unwisely but there is also a significant reputational risk for all future climate change mitigation initiatives.

\section{Disclosure Statement}

No potential conflict of interest was reported by the authors.

\section{Notes}

${ }^{1}$ Note: While the figures reported in the main text are based on the data from UNEP DTU (2015), this figure uses data from June 2013, since the sampling of the interviewees was made on that basis. Since 2013, the numbers of projects and the share of African project's in the investor's pipeline have changed in some cases. The share of African projects of one of the investors interviewed, for instance, rose significantly after compliance market activities had been discontinued. 


\section{References}

Arens, C., Burian, M., Sterk, W., Schnurr, J., Beuermann, C., et al., 2011. The CDM project potential in SubSaharan Africa with focus on selected least developed countries: CDM potential study. Wuppertal Institute and GFA Envest. Wuppertal / Hamburg. Available online at http://jiko-

bmu.de/files/basisinformationen/application/pdf/subsaharan_ldcs_cdm_potentials.pdf.

Arens, C. Wang-Helmreich, H., Hodes, G., and Burian, M., 2011. Assessing Support Activities by International Donors for CDM Development in Sub-Saharan Africa with Focus on Selected Least Developed Countries. Wuppertal Institute and GFA Envest. Wuppertal / Hamburg. Availalble online at http://www.jikobmub.de/files/basisinformationen/publikationen/application/pdf/donor_activities_barrierefrei.pdf

Arens, C., and Burian, M., 2012. Integrating Africa's Least Developed Countries into the Global Carbon Market. Wuppertal/Hamburg. Available online at http://www.jiko-bmu.de/service/download/doc/1241.php

Bayer, P.; Pinkerton, V. M. and Urpelainen, J., 2014. Small and beautiful? The Programme of Activities and the least developed countries. Climate and Development, (ahead-of-print)1-12.

Bellassen, V., Stephan, N., and Leguet, B., 2012. Will there still be a market price for CERs and ERUs in two years time? CDC climat. Climate Brief No 13, May 2012. Paris.

Boyd, E., Hultman, N., Timmons Roberts, J., Corbera, E., Cole, J., Bozmoski, A., Ebeling, J., Tippman, R., Mann, P., Brown, K. and Liverman, D. M., 2009. Reforming the CDM for sustainable development: lessons learned and policy futures. Environmental Science \& Policy, 12(7). 820-31. doi:10.1016/j.envsci.2009.06.007.

Burian, M. and Arens, C., 2014. The clean development mechanism - A tool for financing low carbon development in Africa? In: International Journal of Climate Change Strategies and Management, 6 (2), 166-191. DOI 10.1108/IJCCSM-03-2013-0033

Byigero, A. D., Clancy, J., and Skutsch, M., 2010. CDM in sub-Saharan Africa and the prospects of the Nairobi Framework Initiative. Climate Policy, 10(2), 181-189.

Byrne, R., Smith, A., Watson, J., and Ockwell, D., 2011. Energy Pathways in Low-Carbon Development: From Technology Transfer to Socio-Technical Transformation. STEPS Working Paper 46, Brighton: STEPS Centre.

Castro, P. and Michaelowa, A., 2011. Would preferential access measures be sufficient to overcome current barriers to CDM projects in least developed countries? Climate and Development, 3(2), 123-142. DOI: $10.1080 / 17565529.2011 .582275$.

CDM Loan Scheme, 2015, Email communication with Federico Antonio Canu, May $21^{\text {st }} 2015$.

Costantini, V., and Sforna, G., 2014. Do bilateral trade relationships influence the distribution of CDM projects? Climate Policy, 14(5), 559-580. http://doi.org/10.1080/14693062.2014.871467

Das, K., 2011. Technology Transfer under the Clean Development Mechanism: an empirical study of 1000 CDM projects. The Governance of Clean Development Working Papers 014, Norwich: The University of East Anglia.

Dinar, A., Rahman, S. M., Larson, D. F., and Ambrosi, P., 2008. Factors Affecting Levels of International Cooperation in Carbon Abatement Projects (SSRN Scholarly Paper No. ID 1312269). Rochester, NY: Social Science Research Network. Available online at http://papers.ssrn.com/abstract=1312269

De Gouvello, C., Dayo, F. B., and Thioye, M., 2008. Low-carbon Energy Projects for Development in SubSaharan Africa - Unveiling the Potential, Addressing the Barriers. Washington DC: The World Bank. Department of Energy - Republic of South Africa. (2015). Renewable Energy Independent Power Producer Procurement Programme. Available online at http://www.ipprenewables.co.za/

European Parliament and European Council, 2009. Directive 2009/29/EC of the European Parliament and of the Council of 23 April 2009 amending Directive 2003/87/EC so as to improve and extend the greenhouse gas emission allowance trading scheme of the Community (Text with EEA relevance) (OJ L 140).

Gloaguen, O., and Alberola, E., 2013. One billion tonnes of CO2 avoided by the EU power sector and industry since 2005: half due to energy- climate policies and half due to economic context. CDC climat. Climate Brief No 32, October 2013. 
Fay, J., Kapfudzaruwa, F., Na, L. and Matheson, S., 2012. A comparative analysis of the Clean Development Mechanism in South Africa and China, Climate and Development, 4:1, 40-53.

Hermwille, L., Arens, C., and Burian, M., 2013. Recommendations on the Advancement of the CDM Standardized Baselines Framework. DEHSt Discussion Paper. German Emissions Trading Authority (DEHSt) at the Federal Environment Agency. Berlin.

Jung, M., 2006. Host country attractiveness for CDM non-sink projects. Energy Policy, 34(15), 2173-2184.

Lütken, S., 2012. Penny wise, pound foolish - is the original intention of cost efficient emission reductions through the CDM being fulfilled?, Climate Working Paper Series No. 1, UNEP Risoe, Roskilde.

Lütken, S., 2011. Indexing CDM Distribution: Leveling the Playing Field (CD4CDM Working Paper No. 10). UNEP Risø Centre. Available online at http://www.cd4cdm.org/publications/indexingcdmdistribution.pdf [accessed 7 May 2015].

Mathur, N., Afionis, S., Paavola, J., Dougill A., and Stringer L., 2014. Experiences of host communities with carbon market projects: towards multi-level climate justice, Climate Policy, 14:1, 42-62. DOI: 10.1080/14693062.2013.861728

Mersmann, F. and Arens, C., 2012. Standardised Baselines and LDCs-Concept, Issues, and Opportunities. Wuppertal Institute and GFA Envest. Wuppertal / Hamburg.

Mersmann, F. and Hermwille, L., 2014. Technology Cooperation - Update on the Technology Mechanism and Options for Using Carbon Markets. JIKO Policy Brief 01/2014.

Michaelowa, A., 2007. Unilateral CDM - can developing countries finance generation of greenhouse gas emission credits on their own? International Environmental Agreements (2007) 7:17-34. DOI 10.1007/s10784006-9026-y

Murphy, K., Kirkman, G. A., Seres, S., and Haites, E., 2015. Technology Transfer in the CDM: An Updated Analysis. Climate Policy, 15(1), 127-145.

Niederberger, A. A., and Saner, R., 2005. Exploring the relationship between FDI flows and CDM potential. Transnational Corporations, 14(1), 1-40.

Olsen, K. H. and Fenhann, J., 2008. Sustainable development benefits of clean development mechanism projects: A new methodology for sustainability assessment based on text analysis of the project design documents submitted for validation. Energy Policy 36(8): 2819-2830.

Okubo, Y., and Michaelowa, A., 2010. Effectiveness of subsidies for the Clean Development Mechanism: Past experiences with capacity building in Africa and LDCs. Climate and Development, 2(1), 30-49. DOI: 10.3763/cdev.2010.0032.

Röttgers, D., and Grote, U., 2014. Africa and the Clean Development Mechanism: What Determines Project Investments? World Development, 62, 201-212. Http://doi.org/10.1016/j.worlddev.2014.05.009

Schneider, L., 2007. Is the CDM Fulfilling Its Environmental and Sustainable Development Objectives? An Evaluation of the CDM and Options for Improvement, Report by the Oeko-Institut e.V., Berlin.

Seres, S., Haites, E., and Murphy, K., 2010. The Contribution of the Clean Development Mechanism under the Kyoto Protocol to Technology Transfer. Bonn: UNFCCC.

Silyan, A., 2005. Equitable Distribution of CDM Projects Among Developing Countries, HWWA Report 255, HWWA, Hamburg.

Spalding-Fecher, R., Achanta, A. N., Erickson, P., Haites, E., Lazarus, M., et al., 2012. Assessing the Impact of the Clean Development Mechanism. Luxemburg. Available online at http://www.cdmpolicydialogue.org/research/1030_impact.pdf

Timilsina, G. R.; de Gouvello, C.; Thioye, M. and Dayo, F. B., 2010. Clean Development Mechanism Potential and Challenges in Sub-Saharan Africa. Mitigation and Adaptation Strategies for Global Change, 15(1)93111.

TERI, 2012. Assessing the Impact of the Clean Development Mechanism on Sustainable Development and Technology Transfer. Energy and Resources Institute. 148 pp.

UNEP DTU, 2015. CDM/JI Pipeline Analysis and Database, March 2015. 
UNEP Risø, 2013. CDM/JI Pipeline Analysis and Database, June 2013.

Warnecke, C., Day, T., and Klein, N. (2015). Analysing the Status Quo of the CDM Projects - Status and Prospects. Cologne: NewClimate Institute / Ecofys. Available online at https://newclimateinstitute.files.wordpress.com/2015/05/cdm_evaluation_mainreport_2015.pdf [accessed 23 June 2015].

Wei, S., 2011. Understanding the dominance of unilateral CDM projects in China: Origins and implications for governing carbon markets. GCD Working Paper 016, July 2011.

Winkelman, A. G., and Moore, M. R. (2011). Explaining the differential distribution of Clean Development Mechanism projects across host countries. Energy Policy, 39(3), 1132-1143. http://doi.org/10.1016/j.enpol.2010.11.036

WRI, 2015. CAIT 2.0: WRI's climate data explorer - Total GHG Emissions Excluding Land-Use Change and Forestry - 2011. Available online at http://cait2.wri.org/wri/Country GHG Emissions?indicator\%5B\%5D\%3DTotal\%20GHG\%20Emissions\%20Excluding\%20LandUse $\% 20$ Change $\% 20$ and $\% 20$ Forestry\%26year\%5B\%5D\%3D2011\%26sortDir\%3Ddesc\%26chartType $\% 3$ Dpi e

van Asselt, H. and Gupta, J., 2009. Stretching too far? Developing countries and the role of flexibility mechanisms beyond Kyoto, Stanford Environmental Law Journal 28(2), 311-379. 